\title{
Mortality from circulatory diseases, especially ischaemic heart disease in sea pilots and boatmen in Sweden 1951-84: a retrospective cohort study
}

\author{
L Nyström, B Kolmodin-Hedman, E Jönsson, L Thomasson
}

\begin{abstract}
A cohort of 1455 sea pilots and boatmen employed after 1921 was established. Those identified and alive in $1951(n=1323)$ were linked to the Swedish cause of death register 1951-84. In 21352 person-years 383 deaths were observed among sea pilots compared with $379 \cdot 3$ expected $($ SMR $=101 ; 95 \%$ CI between 99 and 112) and in 12127 person-years the observed number of deaths among boatmen was 136, expected $135.9(S M R=100)$ when Swedish men were used as a reference population. For ischaemic heart disease (IHD) (ICD8: 410-414) the SMR was equal to 96 (obs $=131$, $\exp =137 \cdot 2)$ for sea pilots and 91 (obs $=44$, $\exp =48 \cdot 4$ ) for boatmen. No trend over time or geographical differences could be observed. A healthy worker effect could not explain why there was no excess mortality from IHD.
\end{abstract}

In 1984 a suspicion arose among sea pilots in northern Sweden that too many of their fellow workers died from ischaemic heart disease (IHD). This did not seem unreasonable, as studies of workers with a similar type of work, such as channel pilots in West Germany and the United Kingdom, had indicated an excess mortality from circulatory diseases, especially IHD, in middle aged workers. ${ }^{12}$ Further, Kilbom showed, in a physiological study of six Swedish sea pilots, recording heart rate with a portable ECG tape recorder parallel with time studies, that psychological stress during periods of heavy sea pilot working produced an increased heart rate and thereby increased load on the heart and boarding and leaving a ship in certain circumstances produced high heart rate which, among older sea pilots, implied that they used almost all their physical capacity. ${ }^{3}$

Department of Epidemiology and Health Care Research, University of Umeå, S-901 87 Umeå, Sweden

L Nyström

National Institute of Occupational Health, PO Box 6104, S-900 06, Umeå

B Kolmodin-Hedman, E Jönsson, L Thomasson
After a request from the regional office for sea pilots and boatmen in northern Sweden, an initial study of these groups from the northern district was performed. Six deaths were observed from IHD compared with 10.5 expected-that is, a pronounced underrepresentation. Despite this there was, especially in the trade union, a strong interest in expanding the study to the whole country using a longer follow up period.

The aim of the present study was to clarify if there was an excess mortality from circulatory diseases, especially IHD among sea pilots and boatmen in Sweden. Information about boatmen could be collected at the same time with further effort and they could serve as a comparison group.

\section{Material and methods}

Initially the research group visited the National Swedish Administration of Shipping and Navigation and the regional offices for sea pilots and boatmen to present the aim of the study and ask for excerpts from their register of all male sea pilots and boatmen employed after 1921 for at least six months. Information was obtained concerning civic number, name, parish of birth, home address, working district(s), working position(s), and employment period(s).

Unfortunately, the quality of the register was satisfactory only for those latest employed. For the others, the complete and unique civic number was missing and sometimes even the date of birth was incorrect or missing. Address and parish of birth were available for only a few. After computerisation of the information, the correctness of the civic number was first traced in a microfiche register of Sweden 1972 and then at the parish authorities. For all traced at the parish authorities who were dead at the time of follow up, the date and cause of death were recorded so that those who died before 1951, the year from which the Swedish Cause of Death Register (CDR) is computerised, could be sorted out.

During the follow up period three versions of the International Classification of Diseases (ICD) have been used-ICD-6:1951-7, ICD-7:1958-68, and ICD-8:1969-84 (fig 1). As some of the changes, 


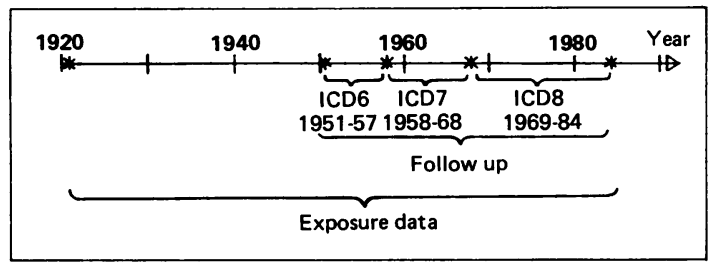

Figure 1 Time period for exposure data, follow up, and different version of International Classification of Diseases applied by Statistics Sweden on Cause of Death Registry.

especially those between ICD-7 and ICD-8, affect chapter VI, circulatory diseases, all cases of interest were sent to Statistics Sweden for. recoding from ICD-7 to ICD 8 .

\section{Statistical methods}

The cohort has been analysed at the Umeå university computer centre. The standard mortality ratio (SMR) has been calculated to compare the observed number of deaths with the expected, using Swedish men as a reference population. Confidence limits were calculated according to Miettinen. ${ }^{4}$

\section{Description of sea pilot work}

In Sweden archipelago trade ship traffic requires the use of a sea pilot. It is locally adjusted to the geomorphological region of the coastal region: abundance of small islands, variation in depth, and the size of the ship. Sweden is nowadays divided into four sea pilot districts: north, central, west, and south and in 1986 about 300 sea pilots and 300 boatmen were working at $\mathbf{4 0}$ stations. During the last years of the period investigated, the number of sea pilot guided sailings have been about 35000 a year.

The formal training of sea pilots starts with a certificate, so that almost all Swedish sea pilots have started their marine careers as sea captains. Formally, they then pass through a couple of years of guided sea pilot work until they reach full responsibility and can work independently as pilots. The sea pilots work on a rotating shift scheme, hence long working hours on a ship might alternate with equally long periods of waiting at home. For a big district, on the west coast, for example, the duty roster changes weekly. Many years ago the waiting period was spent outside their home district but nowadays, for some districts, the pilot can be reached at home.

Boatmen transport the sea pilot from shore out to the ship and they do not have the same educational requirements. Many have worked earlier as fishermen.

There are various ways of boarding ship from a small boat. Ascents and descents from the vessels may vary from climbing up a rope ladder to the sea pilot being lifted aboard or entering through a

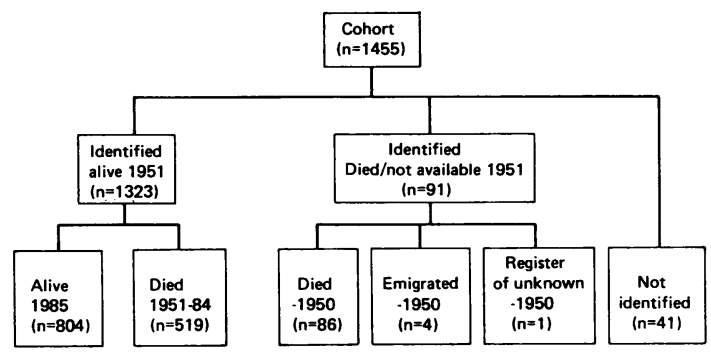

Figure 2 The cohort.

midplaced door. It is important that the sea pilot boards the big ship from the small boat quickly.

The working duties of a sea pilot are a mixture of occasional short bursts of physically heavy work, such as climbing up a ladder, and a psychologically pressing situation with full attention while guiding the ship, interspersed with long periods of waiting at home. Bad weather conditions during the cold and dark winter period often add to the work burden.

\section{Results}

The cohort consisted of 1455 sea pilots and boatmen, of whom 41 could not be identified. Another 91 were lost to follow up in 1951 due to death $(n=86)$, emigration $(n=4)$, and being transferred to the Register of the Unknown ( $=1$ ) (fig 2). Of the remaining 1323,519 died during the follow up period 1951-84.

Figure 3 shows the percentage SMR and the $95 \%$ confidence limits for sea pilots and boatmen for some of the major causes of death from 1951 to 1984 compared with all Swedish men. In 21352 personyears, 383 deaths were observed among sea pilots compared with $379 \cdot 3$ expected $(\mathrm{SMR}=101$ with a $95 \%$ confidence interval between 91 and 112) (table 1). For boatmen there were 136 observed and 135.9 expected deaths in 12127 person years

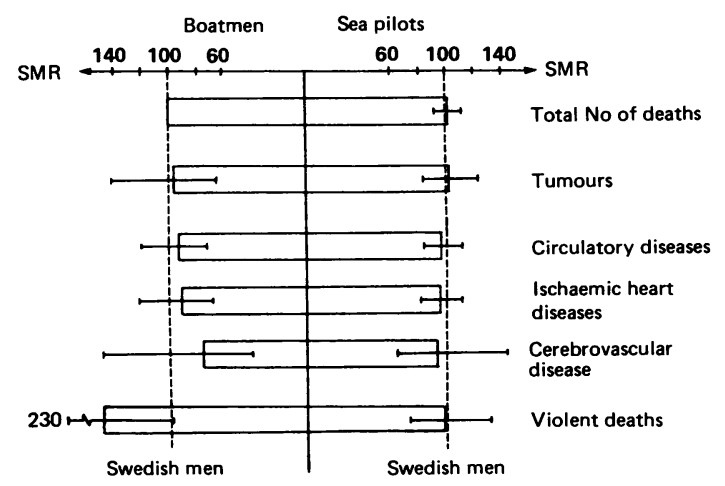

Figure 3 Cause of death pattern for sea pilots and boatmen in Sweden 1951-84. SMR and 95\% CI for SMR.

Reference populations: Swedish men. 
Table 1 Cause of death pattern among sea pilots and boatmen in Sweden 1951-84 compared with all Swedish men. Observed (Obs) and expected (Exp) number of deaths, SMR, and $95 \%$ confidence limits for SMR

\begin{tabular}{llrrrr}
\hline & Cause of death & Obs & Exp & SMR & $\begin{array}{l}\text { SMR; } \\
\text { SMR }\end{array}$ \\
\hline Sea pilots & All causes & 383 & $379 \cdot 3$ & 101 & $91 ; 112$ \\
& Neoplasms & 85 & $83 \cdot 3$ & 102 & $83 ; 123$ \\
& Circulatory diseases & 197 & $203 \cdot 0$ & 97 & $84 ; 112$ \\
& Ischaemic heart disease & 131 & $137 \cdot 2$ & 96 & $82 ; 112$ \\
& Cerebrovascular disease & 34 & 36.0 & 94 & $65 ; 144$ \\
& Violent deaths & 26 & 26.4 & 99 & $74 ; 132$ \\
Boatment & All causes & 136 & $135 \cdot 9$ & 100 & \\
& Neoplasms & 31 & $31 \cdot 9$ & 97 & $66 ; 142$ \\
& Circulatory diseases & 64 & $68 \cdot 1$ & 94 & $73: 120$ \\
& Ischaemic heart disease & 44 & $48 \cdot 4$ & 91 & $68 ; 122$ \\
& Cerebrovascular disease & 8 & $10 \cdot 6$ & 76 & $39 ; 149$ \\
& Violent deaths & 20 & 13.4 & 149 & $97 ; 230$ \\
\hline
\end{tabular}

$($ SMR $=100)$. For IHD there were 131 observed and $137 \cdot 2$ expected deaths among sea pilots, (SMR $96(82 ; 112))$ and among boatmen, 44 observed and 48.4 expected deaths $($ SMR $=91(68 ; 122))$.

The mortality in IHD was studied more in detail. SMRs are shown in fig 4 but the follow up period has been divided into five year periods in order to detect any time trend. For both sea pilots and boatmen there is a significant low mortality in the last period 1981-4 $(S M R=56(34 ; 93)$ for sea pilots and $S M R=43$ $(20 ; 93)$ for boatmen) and for boatmen a significantly high mortality in 1961-5 (SMR $=285(153 ; 532)$ ). Figure 5 shows SMRs by age. The pattern for sea pilots and boatmen is almost identical with the highest mortality in the age group 55-64 and the lowest over 75 . The only significant deviation is for boatmen over $75($ SMR $=29(10 ; 84))$.

In fig 6 SMRs are shown for the five old administrative regions (upper north, lower north, east, south, and west of Sweden). No pattern could be distinguished.

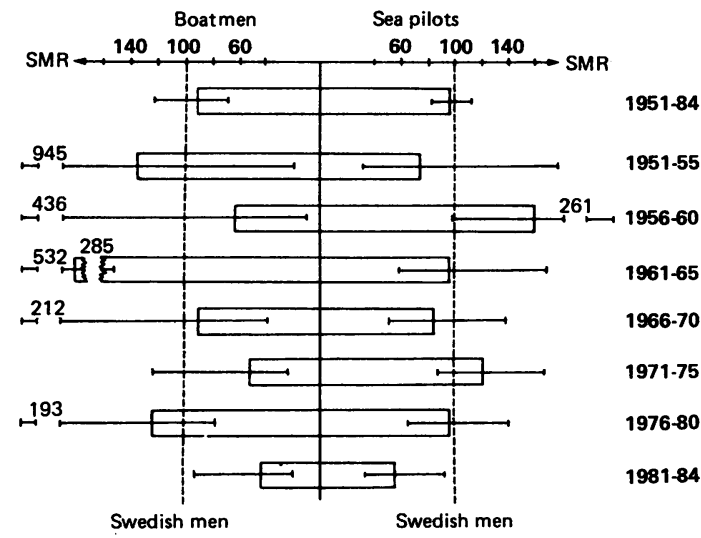

Figure 4 Cause of death pattern for sea pilots and boatmen in Sweden by five year periods. SMR and $95 \% C I$. Reference populations: Swedish men.

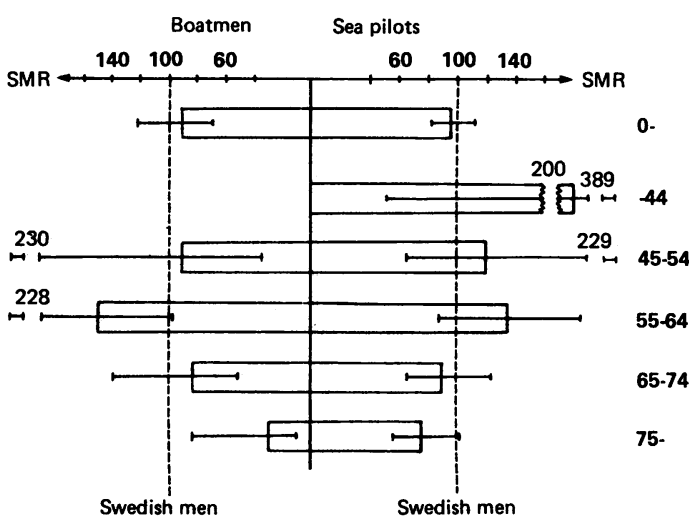

Figure 5 Cause of death pattern for sea pilots and boatmen in Sweden 1951-84 by age. SMR and 95\% CI for SMR. Reference populations: Swedish men.

If the cohort is divided into two strata according to date of employment we found that those employed after 1950 had SMRs between 100 and 115 and those employed before 1950 between 80 and 99. The pattern was consistent for total mortality, circulatory diseases, and IHD for boatmen and sea pilots.

We have also studied the mortality according to years of employment $(0-9,10-19$, and $\geqslant 20)$. For both sea pilots and boatmen the SMRs decrease with number of years employed for all the causes of death studied.

\section{Discussion}

The quality of national cause of death registers has often been questioned, especially concerning the diagnosis IHD. Recently, two physicians validated the death certificates in two Swedish municipalities for those coded by Statistics Sweden with IHD as underlying cause of death. ${ }^{5}$ The validity was ascertained by comparing the death certificates with

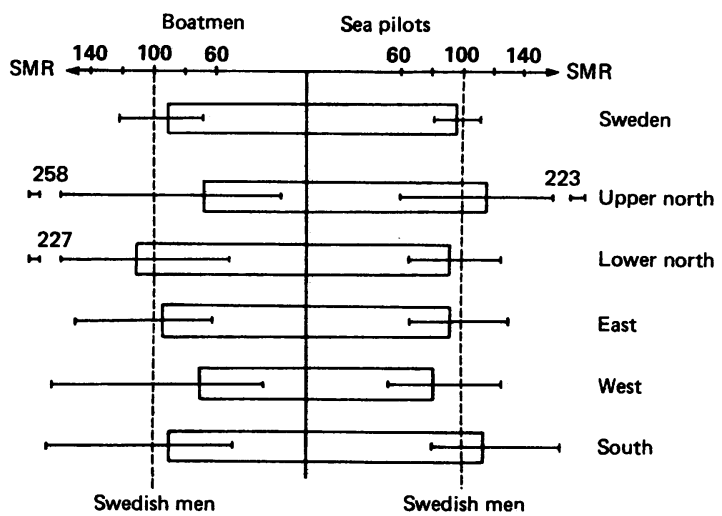

Figure 6 Cause of death pattern for sea pilots and boatmen in Sweden 1951-84. SMR and 95\% CI for SMR. Reference populations: Swedish men. 
Table 2 Comparison of total mortality (ICD-8:000-999) and mortality in circulatory diseases (ICD-8:390-458) and ischaemic heart disease (ICD-8:410-414) between the cohort of sea pilots and boatmen and five published Swedish cohort studies of occupational groups

\begin{tabular}{|c|c|c|c|c|c|}
\hline Reference & Occupational group & Study period & No of person-years & Cause of death & $S M R$ \\
\hline Sandström et al & Smelter workers & $1928-82$ & 130503 & $\begin{array}{l}\text { Total } \\
\text { Circ dis } \\
\text { IHD }\end{array}$ & $\begin{array}{l}115 \\
126 \\
120\end{array}$ \\
\hline Gustafsson et $a l^{l}$ & Chimney sweeps & $1951-82$ & 106462 & $\begin{array}{l}\text { Total } \\
\text { Circ dis } \\
\text { IHD }\end{array}$ & $\begin{array}{l}135 \\
134 \\
135\end{array}$ \\
\hline Gustafsson et al & Dock workers & $1961-80$ & 97076 & $\begin{array}{l}\text { Total } \\
\text { Circ dis } \\
\text { IHD }\end{array}$ & $\begin{array}{l}89 \\
80 \\
77\end{array}$ \\
\hline Andersson et al & Accumulator industry workers & $1951-80$ & 525 men & $\begin{array}{l}\text { Total } \\
\text { Circ dis } \\
\text { IHD }\end{array}$ & $\begin{array}{l}86 \\
82\end{array}$ \\
\hline \multirow[t]{3}{*}{ Lundberg et $a l^{10}$ } & Paint industry workers & $1961-81$ & 6519 & $\begin{array}{l}\text { Total } \\
\text { Cird dis } \\
\text { IHD }\end{array}$ & $\begin{array}{l}88 \\
81 \\
83\end{array}$ \\
\hline & Sea pilots & $1951-84$ & 21352 & $\begin{array}{l}\text { Total } \\
\text { Circ dis } \\
\text { IHD }\end{array}$ & $\begin{array}{r}101 \\
97 \\
96\end{array}$ \\
\hline & Boatmen & & 12127 & $\begin{array}{l}\text { Total } \\
\text { Circ dis } \\
\text { IHD }\end{array}$ & $\begin{array}{r}100 \\
94 \\
91\end{array}$ \\
\hline
\end{tabular}

medical records and clinical or medicolegal necropsies and showed a surprisingly good agreement.

The choice of a reference population is crucial in studies of occupational cohorts and may often be questioned. There are rather large geographical differences in Sweden in mortality from circulatory diseases and IHD; however, there is no reason to believe that geographical standardisation would affect the results since most sea pilots and boatmen have lived in coastal parishes all over the country for most of their lives.

Whether there is a "healthy worker effect" or not can also be questioned. The SMRs can be compared with those from studies of other occupational cohorts using the general population as a reference. Table 2 presents some results from five recently published Swedish cohort studies of occupational groups. The total mortality and the mortality from circulatory diseases and IHD for sea pilots and boatmen is much lower than for smelter workers and chimney sweeps but higher than for dock, accumulator industry, and paint industry workers. ${ }^{6-10}$

It may be relevant to compare the pilots and boatmen in our studied group with dock workers who, to a certain extent, have the same working tasks and conditions. Here a geographical standardisation has been made motivated by the concentration of dock workers to the large ports of Stockholm, Gothenburg, and Malmö. The SMR for circulatory diseases and IHD among dock workers is about $10 \%$ lower than for sea pilots and boatmen despite that standardisation. If the general population had been used as a reference population for the dock workers the difference should have been greater due to the lower mortality from circulatory diseases and IHD in big cities than in the country as a whole.
It has also been argued, especially when studying circulatory diseases, that the reference population should be the working population as the healthy worker effect is more pronounced for these diseases. In an investigation in Finland the total mortality in the working population was calculated to be about $80 \%$ by comparison with the general population and about $90 \%$ by comparison with those who had never worked. ${ }^{11}$

Statistics Sweden constructed a new register by record linkage between the 1960 census and the Cause of Death Register 1961-70, the so called Swedish Death-Environmental-Register. For 19615 they calculated the ratio between the mortality in the working population and the general population by age, sex, and medical diagnosis. There was a decrease in the rate by age for circulatory diseases except violent deaths. For circulatory diseases the decrease in age group $45-49$ was $4 \%$ and in the age group $60-6414 \%$. The corresponding figares for IHD were $6 \%$ and $10 \%$, respectively. If this is taken into account it should imply an increase in the SMR for circulatory diseases and IHD with at the most $10 \%$ - that is, the SMR would still be far from being statistically significant.

Thus even if there is a healthy worker effect of, say, $10-20 \%$ the SMR for IHD among sea pilots and boatmen is far from being statistically significant.

1 Harrington JM. Mortality from coronary artery disease of English channel and Hamburg pilots. Transactions of the Society of Occupational Medicine 1972;22:19-23.

2 Zorn EW, Harrington JM, Goethe H. Ischemic heart disease and work stress in west German sea-pilots. $J$ Occup Med 1977;19:762-5.

3 Kilbom A. Lotsar och lotsningsarbete. Stockholm: Arbetsmedicinska Institutet, 1969. 
4 Miettinen OS. Simple interval estimation of risk ratio. Am J Epidemiol 1974;100:515-6.

5 Sundman L, Jakobsson S, Nyström L, Rosén M. A validation of cause of death certification for ischaemic heart disease in two Swedish municipalities. Scand J Prim Health Care $1988 ; 6 ; 205-11$.

6 Sandström AIM, Wall SEI, Taube A. Cancer incidence and mortality among Swedish smelter workers. Br J Ind Med 1989;46:82-9.

7 Gustafsson P, Gustavsson A, Hogstedt C. Dödsorsaker bland svenska skostensfejare. Arbete Och Hälsa 1986;15.

8 Gustafsson L, Wall S, Larsson L-G, Skog B. Mortality and cancer incidence among Swedish dock workers-a retrospective cohort study. Scand J Work Environ Health 1986;12:22-6.
9 Andersson K, Elinder CG, Hogstedt C, Kjellström T, Spảng G. Dödsorsaker bland kadmium-och nickelexponerade ackumulatorbetare. Arbete Och Hälsa 1983;13.

10 Lundberg I, Andersson I-M, Rosén G. Dödsorsaker och cancersjuklighet hos färgindustriarbetare med lảngvarig exposition för organiska läsningsmedel. Arbete Och Hälsa 1985;33.

11 Vinni K, Hakama M. Defining expected mortality in occupational studies. Scand J Work Environ Health 1979;5:279-303.

Accepted 3 April 1989

\section{Correspondence and editorials}

The British Journal of Industrial Medicine welcomes correspondence relating to any of the material appearing in the journal. Results from preliminary or small scale studies may also be published in the correspondence column if this seems appropriate. Letters should be not more than 500 words in length and contain a minimum of references. Tables and figures should be kept to an absolute minimum. Letters are accepted on the understanding that they may be subject to editorial revision and shortening.

The journal now also publishes editorials which are normally specially commissioned. The Editor welcomes suggestions regarding suitable topics; those wishing to submit an editorial, however, should do so only after discussion with the Editor. 